\title{
Benzyl Benzoate-Loaded Microemulsion for Topical Applications: Enhanced Dermatokinetic Profile and Better Delivery Promises
}

\author{
Gajanand Sharma, ${ }^{1}$ Geeta Dhankar, ${ }^{1}$ Kanika Thakur, ${ }^{1}$ Kaisar Raza, ${ }^{2,3}$ and O. P. Katare ${ }^{1,3}$
}

Received 11 September 2015; accepted 1 December 2015; published online 15 December 2015

\begin{abstract}
Benzyl benzoate (BB) is one of the oldest drugs used for the treatment of scabies and is recommended as the "first-line intervention" for the cost-effective treatment of the disease. Though a promising candidate, its application is reported to be associated with irritation of the skin and eye, resulting in poor patient compliance. Hence, the present study aims to develop BB-loaded topical microemulsion for the safer and effective delivery of BB. Pseudo-ternary phase diagrams with BB as the oily phase itself, along with Tween 80 as surfactant, and mixture of phospholipid and ethanol as the cosurfactant along with aqueous solution as the external phase were constructed and various compositions were formulated. The optimized formulation was characterized for particle-size, zeta-potential, drugcontent, globule-morphology $\mathrm{pH}$, and refractive-index, whereas evaluated for skin permeation, retention, compliance, and dermatokinetics. The nanosized formulation offered threefold higher drug permeation vis-a-vis plain drug solution across LACA mice abdominal skin. The drug retention of the selected formulation was nearly twice of that from the marketed product, assuring depot formulation and sustained release. The skin histopathology revealed the non-irritant nature of the formulation, as no changes in the normal skin histology were observed. The dermatokinetic studies confirmed better permeation and enhanced skin bioavailability of BB to epidermis as well as dermis vis-à-vis the conventional product. The results indicate that the developed lipid-based microemulsion hydrogel can alleviate the concerns associated with $\mathrm{BB}$ and can provide a better and safer delivery option in substantial amounts to various skin layers.
\end{abstract}

KEY WORDS: colloidal delivery; dermal availability; drug delivery; hydrogel; nanoemulsion; retention; scabies.

\section{INTRODUCTION}

Scabies, a highly contagious skin infection, is one of the most common pruritic skin disorders (1). It is common worldwide but is more conspicuous in the areas with poor sanitation and overcrowding. The global prevalence of scabies is around 300 million cases, with larger variations between countries $(2,3)$. It is a neglected parasitic disease and a major health problem of the developing countries. The World Health Organization (WHO) has issued alarming figures of incidence as $9.7-13 \%$ in India (9.7 and 13\%), $23-30 \%$ in children below 6 years in Bangladesh (23-30\% in under 6 years old in slum areas), $4.3 \%$ in Cambodia, and $0.7 \%$ in Malawi. This disease is caused by the mite Sarcoptes scabiei, which burrows into the skin and consumes epidermis and sera of the host, resulting in

\footnotetext{
${ }^{1}$ Division of Pharmaceutics, University Institute of Pharmaceutical Sciences, UGC Centre of Advanced Studies, Panjab University, Chandigarh, 160 014, India.

${ }^{2}$ Department of Pharmacy, School of Chemical Sciences and Pharmacy, Central University of Rajasthan, Bandar Sindri, Dist. Ajmer, Rajasthan 305817 , India.

${ }^{3}$ To whom correspondence should be addressed. (e-mail: drkaisar@curaj.ac.in; katare@pu.ac.in)
}

inflammation, allergy-like reactions, and pruritic lesions (4-7). The currently available treatment options for scabies range from topical scabicides like permethrin, pyrethroids, crotamiton, and lindane to oral medications like antihistamines (8). Benzyl benzoate (BB) is one of the oldest drugs used for the treatment of scabies and is considered as the preferred treatment option for the same (9). The mechanism of action of BB is not well understood, but it is assumed that it acts on the nervous system of the parasite (S. scabiei), resulting in its death $(10,11)$. Benzyl benzoate is the ester of benzyl alcohol and benzoic acid. It occurs as a white solid or colorless oily liquid having a faint aromatic odor. It is completely insoluble in water and glycerol with miscibility in alcohol, choloroform, ether, and oils (11).

Topical BB therapy has been widely used in adults and also in diluted form for children, babies, and lactating mothers (2). In vitro results advocate the superiority of BB in killing scabies mites to permethrin and are more beneficial in severe crusted scabies (12-14). The most common adverse event associated with the use of BB is initial severe burning sensation following local application of concentrated lotion $(25 \% \mathrm{v} /$ v) (13). Other adverse effects include blister formation, crusting, itching, oozing, reddening, and scaling of skin, after repeated use $(13,14)$. Henceforth, clinically, the use of topical 
$\mathrm{BB}$ is not very patient-compliant owing to the associated side effects. Thus, to circumvent the side effects, a suitable carrier system is needed which can suit this very promising drug molecule and revitalize its usage.

Colloidal systems such as microemulsions have been investigated as drug delivery and targeting systems possessing a potential to modify bioavailability, stability, and side effects of various drugs (15-20). Microemulsions (ME) are colloidal dispersions having droplet size in the range of 10 to $100 \mathrm{~nm}$ $(18,21)$. These are composed of oil phase, surfactant, co-surfactant, and aqueous phase in an appropriate ratio. As topical delivery vehicles, MEs tend to increase the local or systemic delivery of drugs through a number of mechanisms including enhancement in the solubility of poorly soluble drugs and by the modification of diffusional barrier of the skin, depending upon the composition of ME (22). MEs provide deeper penetration in the skin layers which results in an effective and controlled delivery of the active agents (23). Micro-emulsified hydrogel-based systems have been selected as the carriers in the present study as they possess oil-like consistency which is suited for easy application on to the infected area including scalp. Pluronic ${ }^{\circledR}$ F-127 (PF-127) has been employed as a gelling agent to achieve the desired ease of application. F-127 is a nonionic surfactant composed of polyoxyethylenepolyoxypropylene copolymers which undergoes sol-gel transition, depending on its concentration and temperature $(24,25)$. Due to its reverse thermal gelation behavior, good solubilization capacity, optical properties, and low toxicity, it appears to have potential application as topical drug delivery system (26). This characteristic has allowed PF-127 to be used as a carrier for various routes of administration including oral, topical, intranasal, vaginal, rectal, ocular, and parenteral routes (27).

Thus, the main objective of the present study was to effectively load BB into the microemulsion based hydrogel for better delivery of the drug to the desired site in a safe and effective manner.

\section{MATERIALS AND METHODS}

\section{Materials}

Free gift samples of Phospholipon S100 were obtained from M/s Phospholipid GmBH (Nattermannalle, Germany). BB, Tween 20, Tween 80, Span 20, and Span 80 were procured from M/s S.D. Fine chemicals Ltd. (Mumbai, India), while absolute ethanol was procured from M/s Bengal Chemicals Ltd. (Kolkata, India). Pluronic $®$ F-127 was procured from BASF Corporation, NJ, USA. All other chemicals and reagents used in the study were of analytical grade and double distilled water was employed in the study.

\section{Construction of Pseudo-Ternary Phase Diagrams}

Pseudo-ternary phase diagrams were constructed employing aqueous titration method at a temperature of $37^{\circ} \mathrm{C}$. For screening of surfactants, pseudo-ternary phase diagrams were constructed employing the surfactant (Tween 80/ Tween 20/Span 20/Span 80) in the mass ratio of 5:1 with the co-surfactant (mixture of phospholipid and ethanol in the mass ratio of 1:5). $\mathrm{BB}$ itself was used as the oil and various clear ratios of oil and $S_{\text {mix }}$ (mixture of surfactant and co- surfactant from 1:9 to 9:1 mass ratio) were titrated against water, till the development of haziness. Similarly, various ratios of aqueous phase and $S_{\text {mix }}$ were prepared and titrated against oil. On the basis of the area of emulsification, the selection of surfactant was made. After selecting the surfactant out of the studied ones, five different phase diagrams were constructed with the varying ratios of surfactant to cosurfactant $\left(S_{\text {mix }}\right)$ varying from mass ratio of 1:1 to 5:1 as, depicted in Table I. The physical state of the microemulsion was marked on the pseudo ternary diagrams with one axis representing aqueous phase, other representing the oil, and the third representing the fixed $S_{\text {mix }}$ ratio. The monophasic/ microemulsion region was identified as the area in the diagram, where clear and transparent formulations were obtained on visual inspection (28).

\section{Selection of Formulations on the Basis of Pseudo-Ternary Phase Diagrams}

The pseudo-ternary phase diagrams were analyzed to identify the microemulsion region. From each diagram constructed, different formulations/points were selected on the basis of minimum amount of emulsifier used in the formulations.

\section{Preparation of Microemulsion}

In brief, the non-aqueous phase (ethanolic solution) consisting of phospholipid, ethanol and Tween 80 was heated to $50-60^{\circ} \mathrm{C}$ with continuous stirring $(15 \mathrm{~min})$ in order to obtain a homogenous solution of surfactant and phospholipid (29). The temperature of the above system was allowed to decrease gradually and BB (equivalent to $20 \%, w / w$ ) was added to it as the oily phase. The required amount of aqueous phase was slowly added under continuous stirring to fetch a clear yellow microemulsion.

\section{Characterization Studies}

According to the ME regions from the phase diagrams, eight ME formulations were prepared and characterized for the following parameters:

\section{Emulsion Attributes}

The formulations were kept randomly for a stipulated period of time (45 days) under the given experimental conditions $\left(37^{\circ} \mathrm{C}\right)$ to assess the sustenance of the characters of the product. The formulations were observed for various

Table I. Composition of Various Ternary Phase Diagrams on the Basis of Ratio of Surfactant to Co-surfactant Used

\begin{tabular}{lll}
\hline $\begin{array}{l}\text { S. } \\
\text { Number }\end{array}$ & $\begin{array}{l}\text { Pseudo-ternary } \\
\text { diagram code }\end{array}$ & $\begin{array}{l}\text { Oil, ratio of surfactant to } \\
\text { co-surfactant }\left(S_{\text {mix })}\right.\end{array}$ \\
\hline 1 & Diagram 1 & BB, Tween 80:co-surfactant (1:1) \\
2 & Diagram 2 & BB, Tween 80:co-surfactant (2:1) \\
3 & Diagram 3 & BB, Tween 80:co-surfactant (3:1) \\
4 & Diagram 4 & BB, Tween 80:co-surfactant (4:1) \\
5 & Diagram 5 & BB, Tween 80:co-surfactant (5:1) \\
\hline
\end{tabular}


macroscopic characters like creaming, cracking, and phase separation.

\section{Drug Content}

The amount of the drug present in the developed systems was determined by extracting the drug in ethanol and subsequent analysis by UV spectrophotometer (UVS-2700, Spectro UV-vis Dual beam, Labomed Inc., USA).

\section{Micromeritics and Zeta Potential}

The mean droplet size and size distribution of prepared microemulsion globules was assessed using DLS technique (Malvern Zetasizer ${ }^{\mathrm{TM}}$, M/s Malvern Instruments Co., Worcestershire, UK). The same equipment was used to determine the zeta potential of the prepared formulations. The value of three subsequent observations was reported as the mean result.

\section{Globule Morphology}

Morphology and structure of the globules of drug-loaded microemulsions was determined using transmission electron microscopy (TEM) installed at Central Instrumentation Laboratory (CIL), Panjab University, Chandigarh, India, and microphotographs were clicked at suitable magnifications.

\section{Measurement of $\mathrm{pH}$}

As the formulations were topical, $\mathrm{pH}$ measurement was essential to ensure the non-irritating nature of the formulations. The $\mathrm{pH}$ of the undiluted formulations was determined using L1-120, Cyber Scan $510 \mathrm{pH}$ meter (Eutech Instruments Pvt. Ltd., Singapore).

\section{Refractive Index}

The optical density of the prepared system was measured using Abbe Refractometer (M/s Shijiazhuang Optical Instrument Factory, Xiamen, China) at room temperature. Refractive index (RI) of the formulations was reported while taking water as reference.

\section{Development of Secondary Topical Vehicle}

Pluronic ${ }^{\circledR}$ F-127 was employed to gel the selected microemulsions to make it rheologically acceptable for topical applications. Pluronic ${ }^{\circledR}$ F-127 equivalent to $(3.6 \%, w / v)$ was dissolved at $4^{\circ} \mathrm{C}$ for $24 \mathrm{~h}$, and after complete solubilization, this aqueous phase was added in the oily phase to give ME gel.

\section{Ex Vivo Permeation Studies}

The animal protocols of the study were approved by the Institutional Animal Ethical Committee (IAEC) of Panjab University, Chandigarh, India, with reference no. 5622/PS. The permeation studies were conducted on excised abdominal skin of LACA mice $(30,31)$. In brief, the animals were sacrificed by cervical dislocation. The skin was removed from the animal with the help of surgical scissors, and hair was removed from the separated skin with the help of surgical blade no. 24. The skin thickness was measured (0.31 to $0.32 \mathrm{~mm}$ ) with the help of a vernier caliper, and dye test was used to test the integrity of the skin. The excised skin was wiped to remove residual adhering fat and further and washed with PBS (pH 6.8). The prepared skin was wrapped in aluminum foil and stored in a deep freezer at $-30^{\circ} \mathrm{C}$ for further use. $(32,33)$ Prior usage methylene blue dye test was performed to assess the skin integrity (34). Ex vivo skin permeation studies were conducted on Franz diffusion cells (PermeGear, Inc., Hellertown, PA, USA). The excised skin was mounted between the donor and receptor compartment exposing an effective area of $3.14 \mathrm{~cm}^{2}$ with sink volume of $30.0 \mathrm{~mL}$ (35). The receptor compartment contained absolute ethanol as diffusion medium to maintain sink condition and its temperature was maintained at $37 \pm 0.5^{\circ} \mathrm{C}$. The prepared formulations (5 mg; equivalent to $1 \mathrm{mg}$ of drug) were applied onto the skin in the donor compartment. Pure drug (oil $1 \mathrm{mg}$ ) was also applied onto the skin of donor compartment for the comparison purpose. The prepared formulations were uniformly spread using flat end of spatula so as to maintain intimate contact with skin (36, 37). At suitable time intervals $(0-24 \mathrm{~h})$, aliquots of $1 \mathrm{~mL}$ each were withdrawn through the sampling port and replaced with equal amount of sink medium to maintain constant receptor compartment volume (23). The samples were analyzed spectrophotometrically, after appropriate dilutions.

\section{Drug Retention Studies in Skin}

After the completion of skin permeation studies, skin tissue mounted on the diffusion cell was removed carefully and washed with distilled water thrice to remove the excess amount of the formulation. The skin was dried under the folds of tissue paper and subsequently weighed. After proper drying, the skin was washed with tissue homogenizer. The homogenate suspension thus obtained was mixed with $20 \mathrm{~mL}$ chloroform-methanol mixture $(2: 1 \mathrm{v} / \mathrm{v})$ and shaken for $2 \mathrm{~h}$ at $37^{\circ} \mathrm{C}$ for extraction of $\mathrm{BB}$. The supernatant was filtered through a $0.45-\mu \mathrm{m}$ membrane filter (M/s Millipore, MA, USA) and spectrophotometrically analyzed for the drug content.

\section{Dermatokinetic Modeling}

The excised skin of the LACA mice was used for the studies. The skin tissue was prepared as discussed in Section 2.7, and the protocol was in consonance with Section 2.8. At the respective sampling times $(0-5 \mathrm{~h})$, the whole skin was removed from the Franz cell and washed thrice to remove any adhering formulation. Portion of the washed skin was soaked in hot water $\left(60^{\circ} \mathrm{C}\right)$ for $30 \mathrm{~s}$ to facilitate the detachment of epidermis from dermis. Both the sections were separated by means of surgical blade and chopped into small pieces, separately, and macerated in $5 \mathrm{~mL}$ of chloroform-methanol mixture $(2: 1 v / v)$ for $24 \mathrm{~h}$ for complete drug extraction. After filtration through a membrane $(0.45 \mu \mathrm{m})$, the filtrate was analyzed using UV spectrophotometer. The obtained data 
were fitted into one-compartment model, as per the Eq. 1(38)

$C_{\text {Skin }}=\frac{K_{p .} C_{\max }^{\mathrm{Skin}}}{(K p-K e)}\left(e^{-K p t}-e^{-K e t}\right)$,

where $C_{\text {skin }}$ is the concentration of drug either in epidermis or dermis at time $t, K_{\mathrm{p}}$ is the dermal permeation constant, $C_{\max }^{\mathrm{Skin}}$ is the maximum concentration achieved either in epidermis or dermis, and $K_{\mathrm{e}}$ is the skin elimination constant. WinNonlin Ver 5.0 software was employed to compute the various dermatokinetic parameters viz. $K_{\mathrm{p}}, C_{\max }^{\mathrm{Skin}}, K_{\mathrm{e}}, T_{\max }^{\text {Skin }}$ (time required to achieve $C_{\max }^{\mathrm{Skin}}$ and area under the curve (AUC $\mathrm{A}_{0-12 \mathrm{~h}}$ ) using the Wagner-Nelson method $(32,38)$.

\section{Skin Compliance Studies}

Male LACA mice (4-6 weeks old; 15-20 g) were divided into three groups, each group consisting of three animals; hairs on the dorsal side of mice were removed with the help of a 0.1 $\mathrm{mm}$ animal hair clipper. The skin was wiped thrice with a saline-wetted cotton swab, and after drying, the formulations $(0.5 \mathrm{~g}$; equivalent to $0.1 \mathrm{~g}$ of $\mathrm{BB})$ were topically applied on the hair skin by uniform spreading within the area of $4 \mathrm{~cm}^{2}$ once a day for 7 days. Group 1 and group 2 animals received topical application of conventional cream and ME hydrogel, respectively. Group 3, on the other hand, was treated only with saline, which served as the control. Prior to each daily application, the formulation remaining on skin was removed carefully and swabbed with saline soaked cotton, and the new dosage was applied. On completion of study, the animals were then sacrificed by cervical dislocation; skin samples were removed and fixed in $10 \%$ formalin solution. The skin samples obtained were stained with hematoxylin and eosin. The stained skin samples were observed microscopically for the histopathological changes (31).

\section{STABILITY STUDIES}

All the prepared microemulsion formulations were sub-

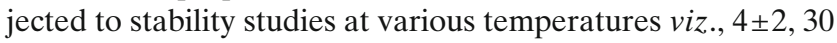
\pm 2 , and $45 \pm 2^{\circ} \mathrm{C}$ for 45 days in sealed ampoules. After every 7 days, the drug content was determined, as per the method described in drug content studies.

\section{Statistical Analysis}

The results were statistically analyzed using one-way ANOVA followed by post hoc analysis using Student's $t$ test. Statistical significance was considered at $p<0.05$.

\section{RESULTS AND DISCUSSION}

\section{Screening of Oils, Surfactants, and Co-Surfactants for ME}

Selection of oily phase is the most crucial step for the formulation of microemulsions. BB itself is oily in nature and is being used in the concentration range of $10-20 \%$; hence, in the present study, it was used oil as such. Despite all this, it is also reported to possess cosolvency properties (39).

From the pseudo-ternary phase diagrams as portrayed in Fig. 1, it is clearly vivid that Tween 80 was able to offer better emulsification region vis-à-vis other employed non-ionic surfactants. However, there were no issues of miscibility of the drug with the studied surfactants. On the basis of maximum emulsification, Tween 80 was selected
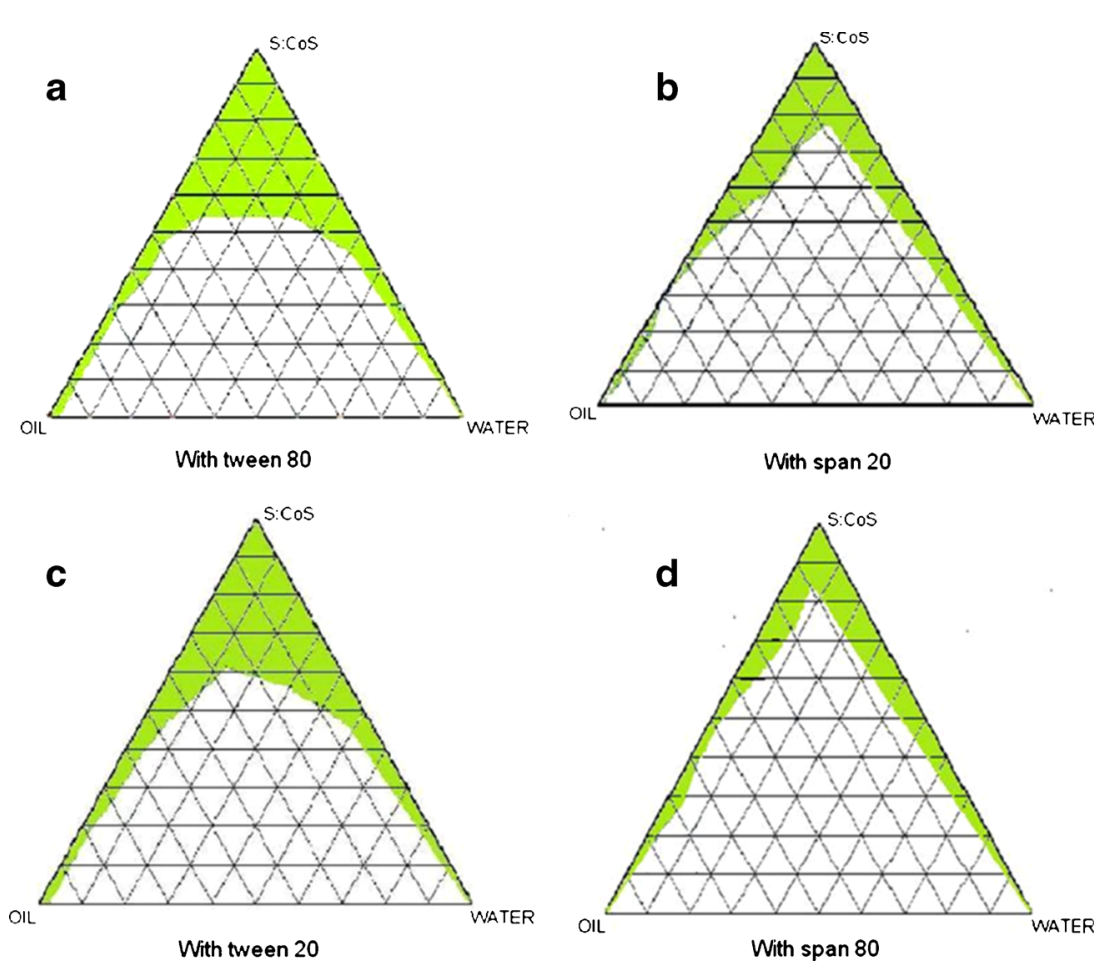

Fig. 1. Pseudo-ternary phase diagrams employing different surfactants as: a Tween 80 ; b Span 20; c Tween 20 and d Span 80 

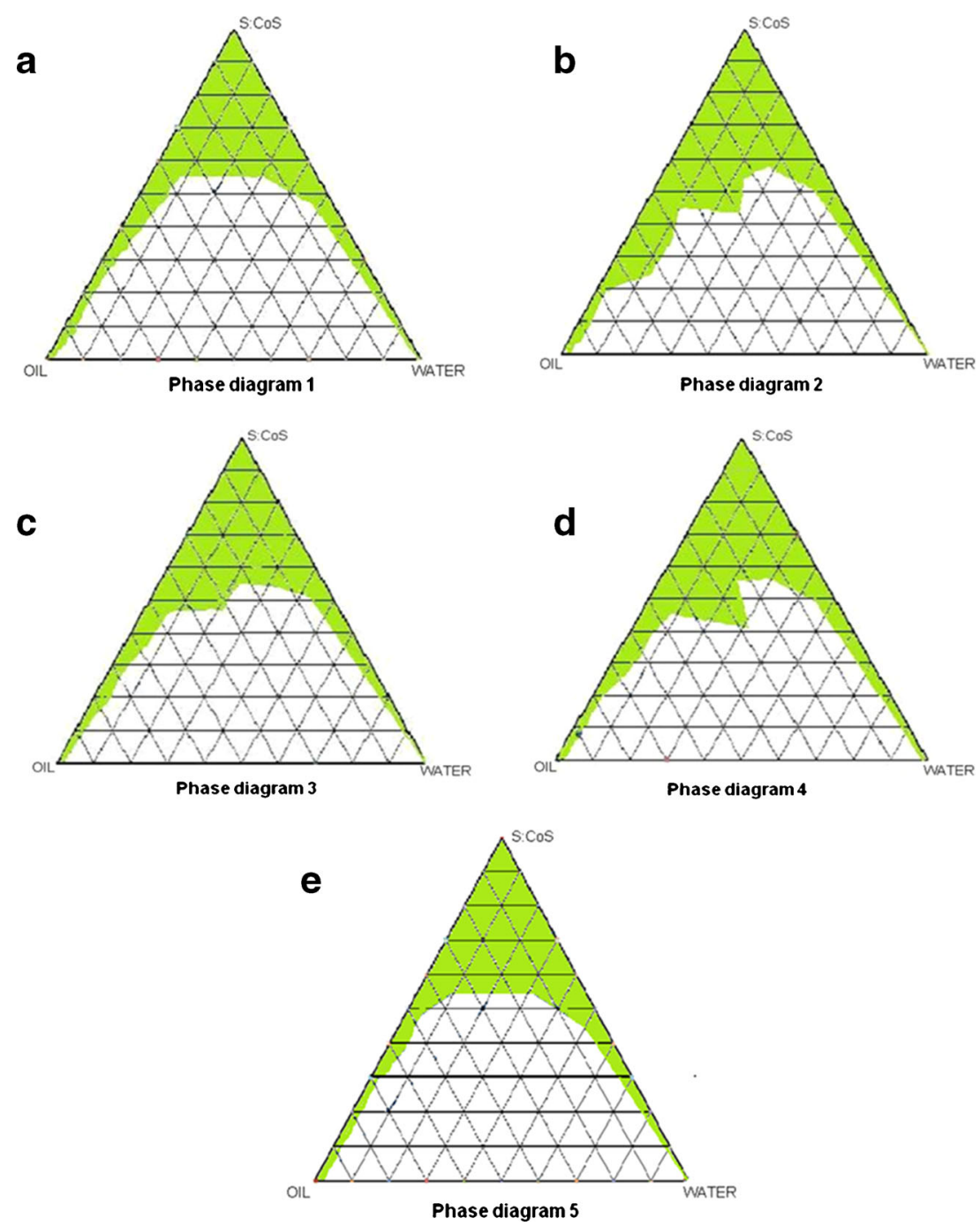

Fig. 2. Various pseudo-ternary phase diagrams with surfactant to co-surfactant ratios as: a $1: 1 ;$ b $2: 1 ;$ c $3: 1 ;$ d $4: 1$ and e $5: 1$

as the surfactant, as higher concentrations of BB (20\%) can be loaded with use of this emulsifier. Tween 80 is a well-established non-ionic surfactant for its biocompatibility and better emulsification characteristics (17). In addition to this, there are various studies which report that Tween 80 when incorporated in microemulsion enhances the skin permeation of drugs $(36,38)$.

On the other hand, presence of co-surfactant is not mandatory, but its incorporation reduces the interfacial tension which further enhances the stability of microemulsions $(37,40)$. In the present study, phospholipid S100 along with ethanol was used as the co-surfactant with an aim to exploit the biocompatibility of phospholipid and the permeation enhancement from ethanol $(36,37,41)$. Ethanol has the capability to reduce the rigidity of the phospholipid condensed films, which is needed for the microemulsion globule formation $(41,42)$. The presence of co-surfactant ultimately decreases the bending stress of the interface and imparts sufficient flexibility to take up different curvatures required to form ME over a wide range of composition (43).

\section{Construction of Ternary Phase Diagram and Selection of Formulations}

The relationship between the phase behavior of a mixture and its composition can be established with the aid of a phase

Table II. The Compositions of the Selected Formulations

\begin{tabular}{cccc}
\hline $\begin{array}{c}\text { Formulation } \\
\text { code }\end{array}$ & $\begin{array}{c}\text { Percentage } \\
\text { of oil }\end{array}$ & $\begin{array}{c}\text { Percentage of } \\
\text { aqueous phase }\end{array}$ & $\begin{array}{c}\text { Percentage of } \\
\text { emulsifier }\end{array}$ \\
\hline
\end{tabular}

Formulation from 1, 3, and 5 pseudo-ternary phase diagrams

$\begin{array}{llll}\text { G11 } & 20 & 24 & 56 \\ \text { G21 } & 15 & 28 & 57 \\ \text { G13 } & 20 & 25 & 55 \\ \text { G23 } & 15 & 27 & 53 \\ \text { G15 } & 15 & 29 & 56 \\ \text { G25 } & 20 & 24 & 56\end{array}$

Formulation from two to four pseudo-ternary phase diagrams
G12
15
25
60
G14
15 
Table III. Physiochemical Characteristics of Studied ME Formulations

\begin{tabular}{|c|c|c|c|c|}
\hline Formulation code & Drug content (\%) & Globule size (nm) & Zeta potential $(\mathrm{mV})$ & RI \\
\hline G11 & 99.51 & 104.8 & 0.218 & 1.438 \\
\hline G21 & 99.78 & 136 & 0.398 & 1.418 \\
\hline G12 & 99.81 & 446.9 & 0.0416 & 1.437 \\
\hline G13 (o) & 99.62 & - & - & 1.442 \\
\hline $\mathrm{G} 23$ & 99.66 & 2378 & 0.258 & 1.436 \\
\hline G14 & 99.91 & 240 & 0.148 & 1.450 \\
\hline G15 & 99.99 & 235.1 & 0.239 & 1.425 \\
\hline G25 (o) & 99.49 & - & - & 1.432 \\
\hline
\end{tabular}

(o) not taken for studies as were are unstable, $R I$ refractive index

diagram (44). Figure 2 shows the obtained phase diagrams from all the $S_{\text {mix }}$ compositions.

There are no reports of the proper basis of selecting different microemulsion formulations from a phase diagram, as hundreds of formulations can be prepared from microemulsion region of a single diagram (17). Two formulations were selected from pseudo-ternary phase diagrams 1, 3, and 5, and one point each was selected from pseudo-ternary phase diagrams 2 and 4 . The points were selected on the basis of fixed amount of oil to be taken (20 and $15 \%$ ), as drug was acting as oil phase. The formulae and codes of the selected formulations have been shown in Table II.

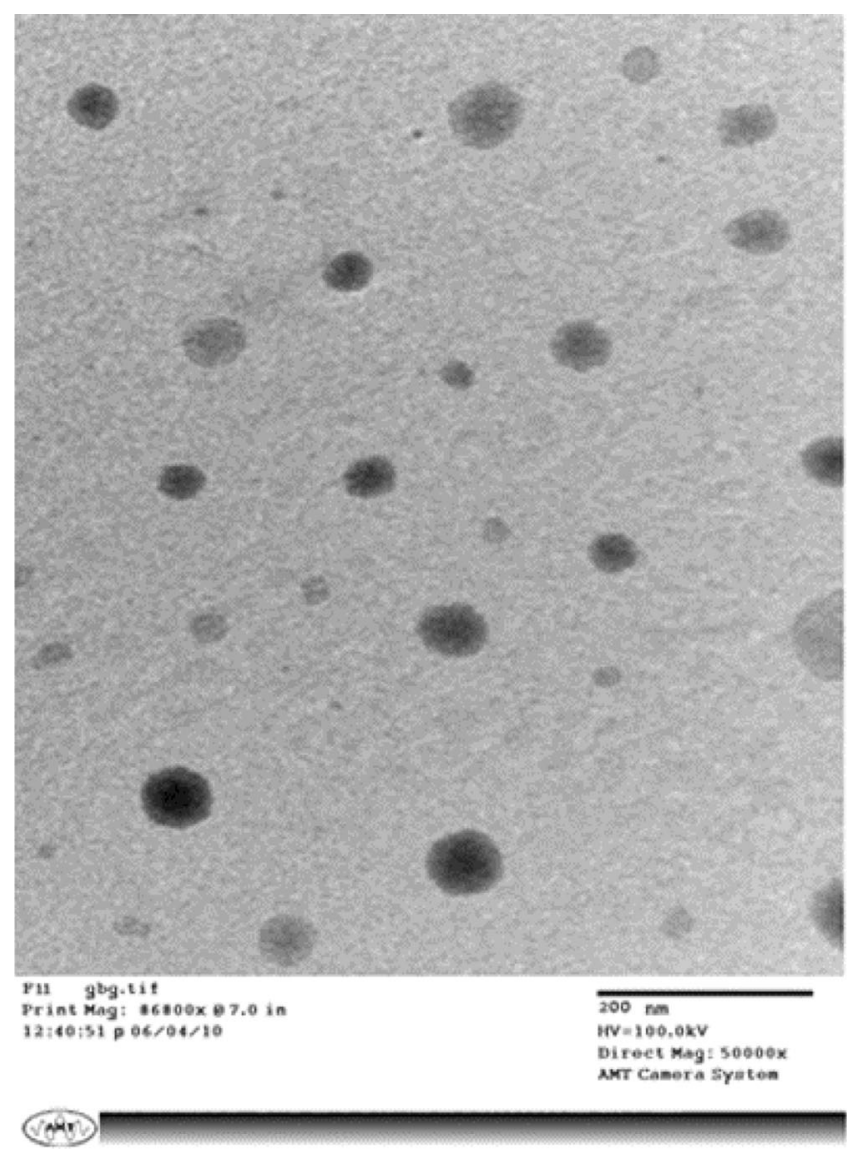

Fig. 3. TEM photograph of BB-loaded microemulsion $(50,000 \times)$

\section{Characterization of Microemulsions}

The results of the characterization studies indicated successful development of microemulsion formulations of BB with optimum characteristics. The dispersed systems of ME formulations were found to be macroscopically identical, i.e., homogeneous, transparent without any precipitates, optically isotropic, and yellow colored. The physicochemical parameters of microemulsions are tabulated in Table III. The drug content of all eight formulations was in the range of 99.49 to $99.99 \%$ with mean value of $99.72 \%$. The average size of the ME globules ranged from 104.8 to $2378 \mathrm{~nm}$, while the PDI value was found in the range of 0.0416 to 0.398 . Higher values of drug content assured successful material transfer of the active drug during various formulation processes. The zeta potential values were found to be near zero, which may be ascribed to the non-ionic nature of the surfactant and co-surfactant used (i.e., Tween 80 and phospholipid S100). However, such components are reported to provide better stability to the formulation against any ionic interactions. Out of all the formulations, the mean diameter of G11 was found to be the smallest i.e., $104.8 \mathrm{~nm}$. The zeta potential was found to be $0.218 \mathrm{mV}$ for the selected formulation. This may be attributed to the non-ionic nature of both surfactants and co-surfactant used. They do not impart any charge to the droplet surface and provide better stability to the microemulsion against any ionic interactions. The refractive index values were of the studied formulations and were found to range between 1.418 and 1.450 against water. The consistency in RI values of

Table IV. Permeation Profile and Drug Retention of BB from Various Formulations $(n=3)$

\begin{tabular}{llll}
\hline $\begin{array}{l}\text { Formulation } \\
\text { code }\end{array}$ & $\begin{array}{l}\text { Percentage of } \\
\text { BB permeated } \\
(\% \pm \mathrm{SD})\end{array}$ & $\begin{array}{l}\text { Permeation } \\
\text { flux }\left(\mu \mathrm{g} / \mathrm{cm}^{2} / \mathrm{h}\right. \\
\pm \mathrm{SD})\end{array}$ & $\begin{array}{l}\text { Amount } \\
\text { retained } \\
(\% \pm \mathrm{SD})\end{array}$ \\
\hline$\mu 11$ & $67.45 \pm 0.100$ & $8.59 \pm 0.51$ & $0.920 \pm 0.010$ \\
$\mathrm{G} 21$ & $38.37 \pm 0.243$ & $5.09 \pm 0.44$ & $0.470 \pm 0.023$ \\
G12 & $51.44 \pm 0.121$ & $6.83 \pm 0.42$ & $0.468 \pm 0.031$ \\
G23 & $50.75 \pm 0.089$ & $6.73 \pm 0.23$ & $0.695 \pm 0.042$ \\
G14 & $47.55 \pm 0.203$ & $6.31 \pm 0.12$ & $0.557 \pm 0.033$ \\
G15 & $60.35 \pm 0.229$ & $8.01 \pm 0.51$ & $0.530 \pm 0.019$ \\
\hline
\end{tabular}




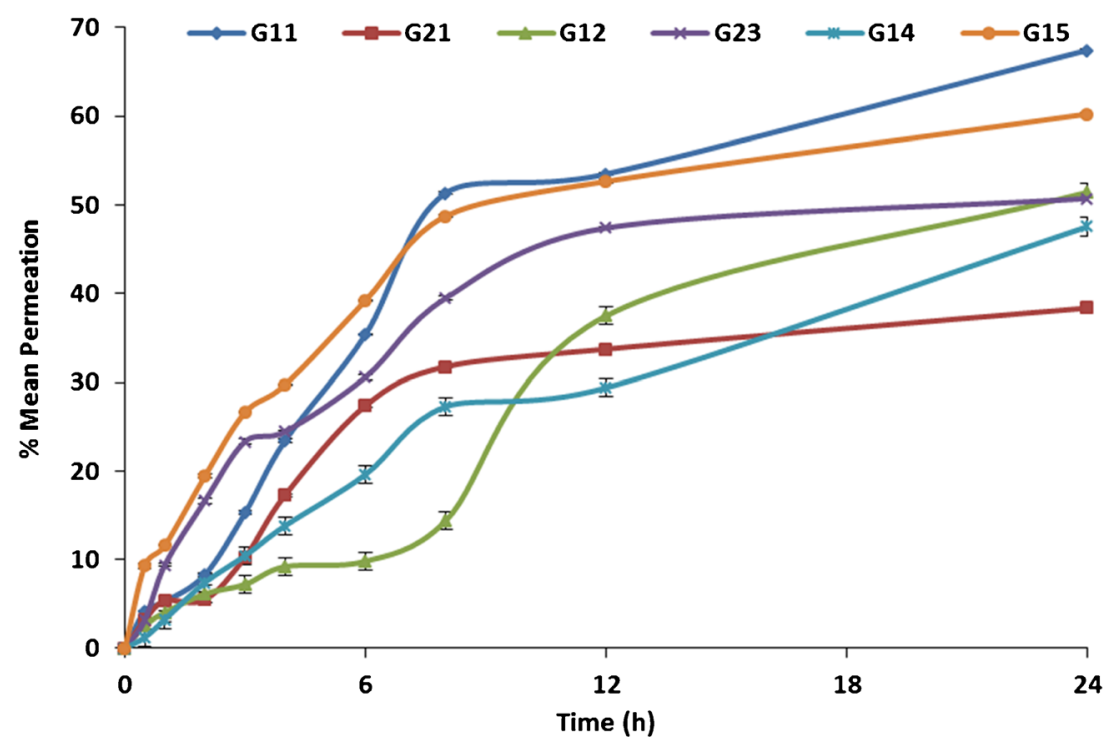

Fig. 4. Plot between mean percentage of $\mathrm{BB}$ permeated versus time from various tested formulations. Each cross bar indicates average value $\pm \operatorname{SD}(n=3)$

all developed formulations is an indication of regular microemulsion structure (44).

\section{Morphology and Structure}

The optimized formulation was viewed microscopically through TEM. The image depicts the spherical nature of the globules, revealing that the globules are covered by additional coating as shown in Fig. 3.

\section{Ex Vivo Skin Permeation Studies}

The percutaneous permeation parameters of the tested ME formulations are depicted in Table IV. The permeation behavior of the developed formulations was assessed by analyzing the permeation flux values as well as graphic relationship of the amount released with respect to time, as depicted in Fig. 4.

The order of amount of drug permeation was found to be as follows:

G11 $(67.45 \pm 0.10 \%)>\mathrm{G} 15(60.35 \pm 0.23 \%)>\mathrm{G} 12(51.44 \pm$ $0.12 \%) \approx \mathrm{G} 23(50.75 \pm 0.09 \%)>\mathrm{G} 14(47.55 \pm 0.20 \%)>\mathrm{G} 21$ $(38.37 \pm 0.24 \%)$, while the order of drug permeation flux was observed as:

G11 $\left(8.59 \pm 0.51 \mu \mathrm{g} \mathrm{cm}^{-2} \mathrm{~h}^{-1}\right)>\mathrm{G} 15\left(8.01 \pm 0.51 \mu \mathrm{g} \mathrm{cm}^{-2} \mathrm{~h}^{-1}\right)>$ G12 $\left(6.83 \pm 0.01 \mu \mathrm{g} \mathrm{cm}^{-2} \mathrm{~h}^{-1}\right)>\mathrm{G} 23\left(6.73 \pm 0.23 \mu \mathrm{g} \mathrm{cm}^{-2} \mathrm{~h}^{-1}\right)>$ G14 $\left(6.31 \pm 0.12 \mu \mathrm{g} \mathrm{cm}^{-2} \mathrm{~h}^{-1}\right)>\mathrm{G} 21\left(5.09 \pm 0.44 \mu \mathrm{g} \mathrm{cm}^{-2} \mathrm{~h}^{-1}\right)$.

It was observed that the maximum drug permeation and maximum permeation flux values were for G11 (Tween $80=$ $28 \%, \mathrm{PL}=23.33 \%$, and ethanol $=4.67 \%$ ), while the similar formulation G21 (Tween $80=38 \%, \mathrm{PL}=15.83 \%$, and ethanol= $3.16 \%$ ) offered very low permeation and poor permeation flux values. Despite from same phase diagram 1, differences in composition as well as oil amount (20\% in G11 vis-à-vis $15 \%$ in G21) are the regions for difference in permeation profiles. The next higher permeation flux after G11 was observed for G15 (Tween $80=46.67 \%, \mathrm{PL}=7.78 \%$, and ethanol $=1.55 \%$ ) which was selected and obtained from ternary phase diagram 5. Interestingly, two contradicting observations were found to be prevalent in this composition. Firstly, it contained the maximum amount of Tween 80 (46.67\%), out of all the studied compositions, which is reported to emulsify sebum and extract skin lipids that enhance the thermodynamic coefficient of the drug, allowing it to penetrate into the cells more effectively $(45,46)$. On the other hand, the amount of phospholipid was observed to be least in G15 $(7.78 \%)$. Hence, it was inferred that the permeation effect from phospholipid was far greater than that from Tween 80 . This relatively lower permeation flux can be ascribed to the lower concentration of phospholipid present vis-à-vis the formulation G11. The lower amount of phospholipid seems to be more responsible and the deciding factor than the increased amount of surfactant in determining the drug permeation profile.

In general, it was observed that the enhancement in drug permeation was most affected by the total amount of surfactant(s) (cumulative effect of Tween 80, phospholipid, and ethanol), followed the amount of BB. The findings are in consonance with the previous reports indicating the substantial effect of surfactant amount and type on the skin permeation of drugs $(47,48)$.

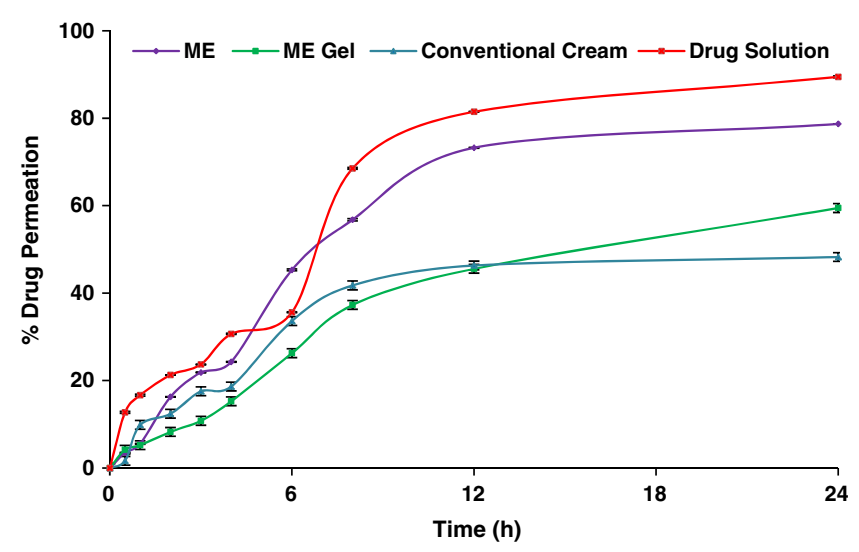

Fig. 5. Percutaneous permeation profile of the selected formulation and other reference products. Each cross bar indicates average value \pm $\mathrm{SD}(n=3)$ 


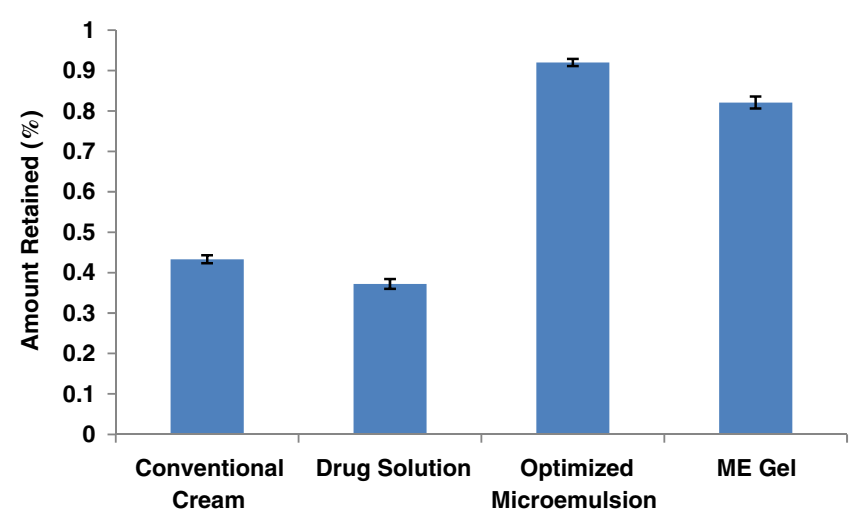

Fig. 6. Bar diagram showing the mean percent drug retention in the skin from various formulations. Each cross bar indicates average value $\pm \mathrm{SD}(n=3)$

\section{Drug Retention Study}

The results of the study are displayed in Table IV. In this study, drug retention analysis was carried out after $24 \mathrm{~h}$ for six remaining formulations. The highest drug retention was observed in G11, followed by G23. Hence, the formulation $\mathrm{G} 11$ offered the maximum permeation flux, highest percentage permeation, as well as the desired drug retention, hence, was selected as the final formulation for further evaluation.

\section{Comparative Evaluation of the Optimized ME Formulation}

\section{Ex Vivo Skin Permeation Study}

The ex vivo skin permeation profiles of microemulsion, microemulsion hydrogel, commercial cream, and drug solution through excised abdominal skin of mice are as shown in Fig. 5. The release behavior of the selected formulation was assessed by analyzing the flux value as well as the graphic relationship.

The order of release flux obtained is in the following order: drug solution (11.98 $\left.\mu \mathrm{g} \mathrm{cm} \mathrm{cm}^{-2} \mathrm{~h}^{-1} \pm 0.92\right)$
$>$ microemulsion $\left(8.95 \mu \mathrm{g} \mathrm{cm} \mathrm{cm}^{-2} \mathrm{~h}^{-1} \pm 0.77\right)>$ microemulsion gel $\left(7.59 \mu \mathrm{g} \mathrm{cm} \mathrm{cm}^{-2} \mathrm{~h}^{-1} \pm 0.61\right)>$ conventional cream (6.96 $\mu \mathrm{g} \mathrm{cm}^{-2} \mathrm{~h}^{-1} \pm 0.53$ ). The permeation flux of drug solution was the highest, followed by microemulsion and microemulsion hydrogel which was found to be higher as compared to the conventional cream $(p<0.05)$. The surfactants in $\mathrm{ME}$ act as permeation enhancers and reduce the barrier of stratum corneum. Additionally, ME acts as the nanocarrier for drug providing a large surface area for drug transfer to skin and high drug concentration within the upper layers of the skin which results in a higher concentration gradient as the driving force for topical drug delivery.

\section{Drug Retention Studies in Skin}

The drug retention studies were performed to compare the above mentioned formulations of BB. Figure 6 shows the drug retention profile of various formulations of BB. The optimized formulation had three times higher drug deposition capacity than commercial cream and plain drug solutions, respectively. This might be due to the faster release observed for the drug from G11 compared to conventional cream and drug solution, thereby more drug penetrates into the skin by which more amount of drug retains in the skin. Hence, it can be inferred from drug retention study that the optimized formulation, G11, is an efficient delivery vehicle for the safe and effective treatment of scabies.

\section{Dermatokinetic Modeling}

Figure $7 \mathrm{a}, \mathrm{b}$ shows the distribution of drugs in the epidermis and dermis of the LACA mice skin. Delivery of $\mathrm{BB}$ in the skin layers by $\mathrm{ME}$ gel was found to be significantly greater $(p<0.05)$ than that from the conventional cream. Table $\mathrm{V}$ gives the numeric values of $\mathrm{AUC}_{0-12} \mathrm{~h}, C_{\mathrm{max}}^{\text {Skin }}$, skin penetration rate constant $\left(K_{\mathrm{p}}\right)$, $T_{\text {max }}^{\text {Skin }}$, and skin elimination rate constant $\left(K_{\mathrm{e}}\right)$. It is vivid from the results that the biological half-life of the drug was enhanced by $\mathrm{ME}$ in both the skin layers, and $T_{\max }$

\section{a}

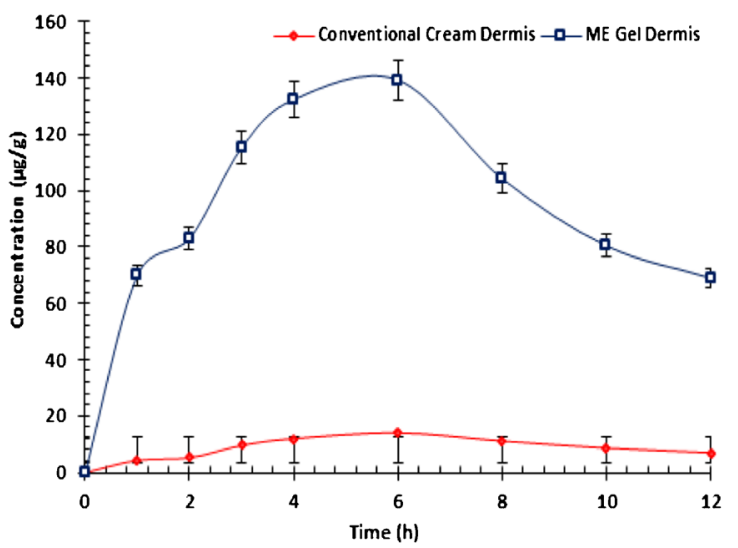

b

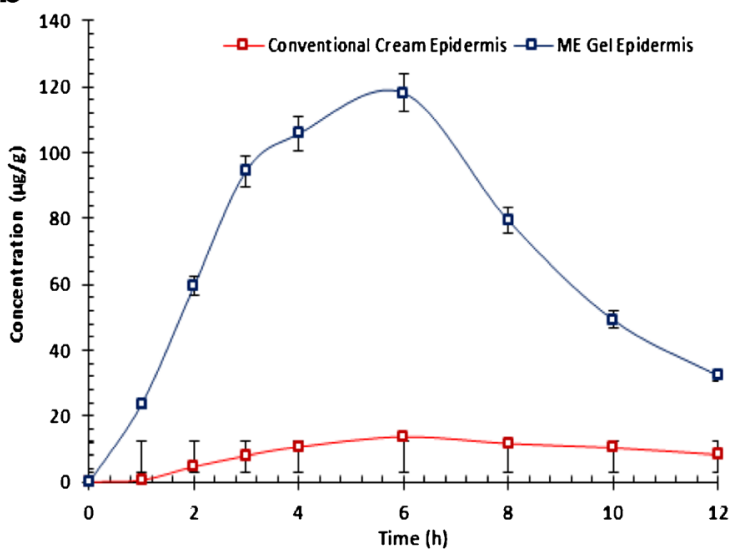

Fig. 7. Dermatokinetic profile showing the drug concentration in a the dermis and $\mathbf{b}$ the epidermis, at various time points. Each cross bar indicates average value $\pm \mathrm{SD}(n=3)$ 
Table V. Dermatokinetic Parameters $($ Mean \pm SD) of BB-Loaded Topical Formulations in the Epidermis and Dermis of LACA Mice $(n=3)$

\begin{tabular}{|c|c|c|c|c|}
\hline \multirow[t]{2}{*}{ Dermatokinetic parameters } & \multicolumn{2}{|c|}{ ME Gel } & \multicolumn{2}{|c|}{ Conventional cream } \\
\hline & Epidermis & Dermis & Epidermis & Dermis \\
\hline $\operatorname{AUC}_{0-12 \mathrm{~h}}\left(\mu \mathrm{g} \mathrm{cm}^{-2} \mathrm{~h}\right)$ & $740.36 \pm 286.75$ & $1049.0 .56 \pm 174.17$ & $771.83 \pm 156.66$ & $559.27 \pm 295$ \\
\hline$C_{\max }\left(\mu \mathrm{g} \mathrm{cm}^{-2}\right)$ & $61.16 \pm 6.68$ & $83.68 \pm 4.23$ & $35.24 \pm 5.6$ & $36.02 \pm 9.52$ \\
\hline$T_{\max }(\mathrm{h})$ & $4.45 \pm 0.99$ & $4.61 \pm 0.39$ & $7.86 \pm 2.39$ & $5.71 \pm 0.75$ \\
\hline $\mathrm{K}_{\mathrm{a}}\left(\mathrm{h}^{-1}\right)$ & $3.07 \pm 554.99$ & $3.13 \pm 37.29$ & $4.41 \pm 35.06$ & $3.96 \pm 142.45$ \\
\hline $\mathrm{K}_{\mathrm{e}}\left(\mathrm{h}^{-1}\right)$ & $3.09 \pm 558.98$ & $3.26 \pm 39.04$ & $6.84 \pm 66.43$ & $3.95 \pm 141.8$ \\
\hline
\end{tabular}

was reduced drastically. $C_{\max }$, in both the layers, and AUC in the dermis was significantly enhanced. The results unequivocally confirmed that the ME has the potential to enhance the delivery of $\mathrm{BB}$ and increase its topical bioavailability $v i s-\grave{a}-v i s$ the conventional product.

\section{Skin Compliance Studies}

Photomicrographs of the skin samples treated with ME hydrogel showed the absence of any marked changes in the normal histology vouching better tolerability of the ME-based formulation as depicted in Fig. 8a-c. This may be attributed to the encasement of the drug within the biocompatible components viz., phospholipid and surfactant; however, the mice skin treated with the conventional cream showed marked irritation such as infiltration of inflammatory cells, epidermis thickening, and peeling of the epidermis from the dermis which is considered evidence of irritation, thus indicating its non-compliant nature.

\section{STABILITY STUDIES}

The drug content (Table VI) and physical attributes (Table VII) of optimized formulation were studied at 4

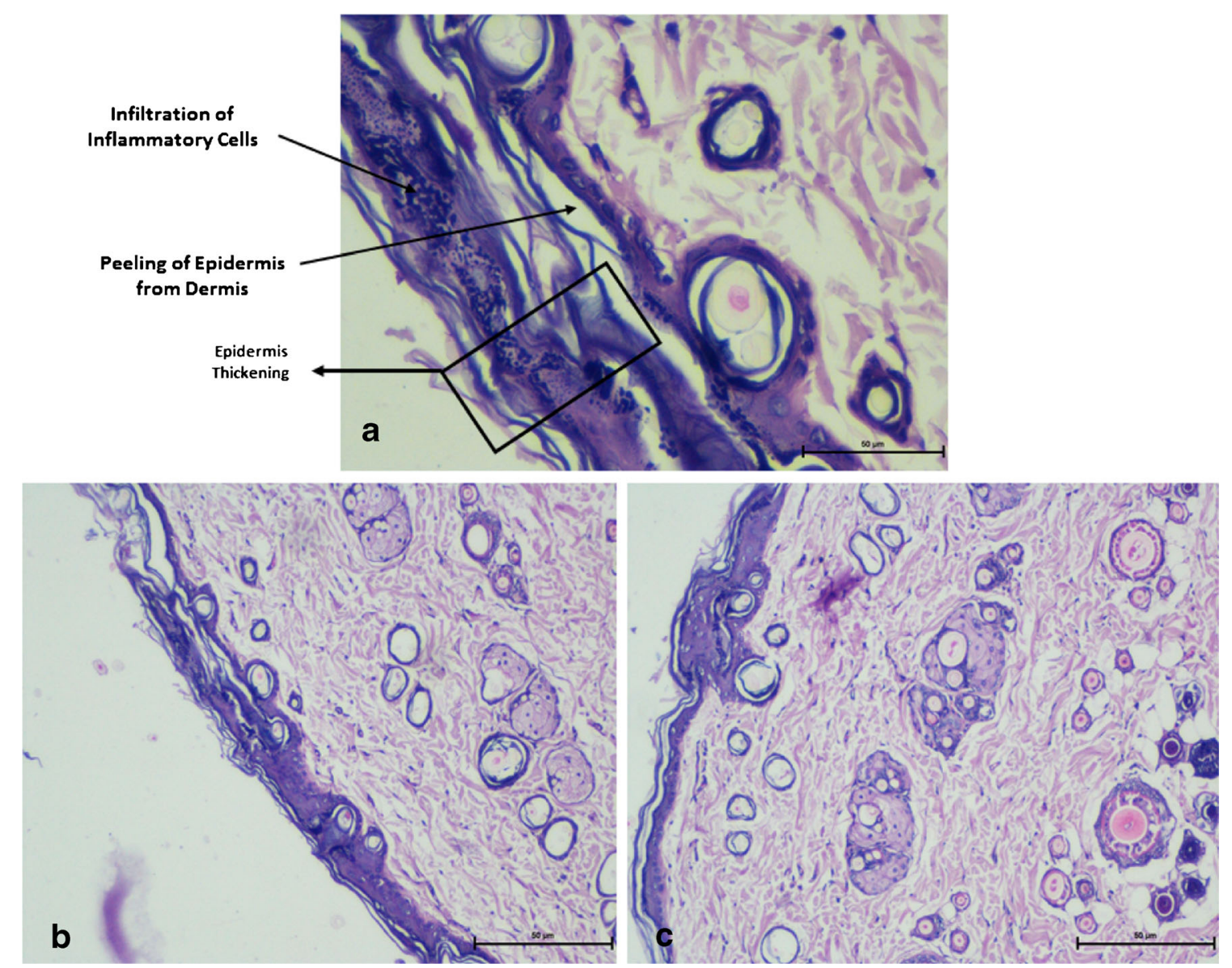

Fig. 8. Microphotographs of skin sections treated with a conventional cream, b ME hydrogel, and $\mathbf{c}$ saline solution (control) 
Table VI. Drug Content of Optimized Formulation at Various Temperatures $(n=3)$

\begin{tabular}{lllll}
\hline S. Number & Days & \multicolumn{3}{c}{ Percent drug content remaining } \\
\cline { 3 - 5 } & & $4 \pm 2^{\circ} \mathrm{C}$ & $30 \pm 2^{\circ} \mathrm{C}$ & $45^{\circ} \mathrm{C} \pm 2^{\circ} \mathrm{C}$ \\
\hline 1 & 1 & $99.51 \pm 0.009$ & $99.51 \pm 0.005$ & $99.51 \pm 0.008$ \\
2 & 7 & $99.24 \pm 0.010$ & $99.34 \pm 0.007$ & $99.32 \pm 0.004$ \\
3 & 14 & $99.01 \pm 0.007$ & $99.16 \pm 0.009$ & $99.27 \pm 0.006$ \\
4 & 28 & $98.76 \pm 0.011$ & $98.76 \pm 0.010$ & $98.13 \pm 0.007$ \\
5 & 35 & $98.45 \pm 0.010$ & $98.59 \pm 0.011$ & $98.09 \pm 0.010$ \\
6 & 45 & $98.41 \pm 0.009$ & $98.52 \pm 0.010$ & \\
Net loss & $1.10 \pm 0.009$ & $0.99 \pm 0.023$ & $0.54 \pm 0.007$ \\
\hline
\end{tabular}

$\pm 2,30 \pm 2$, and $45 \pm 2^{\circ} \mathrm{C}$ for a period of at least 8 weeks. After every 7 days, percentage drug content was determined as per the method described in drug content studies of preliminary microemulsion formulations. The mentioned results indicate that the optimized formulation was stable at all the temperatures for 45 days; however, at $30 \pm 2$ and $45 \pm 2^{\circ} \mathrm{C}$, the microemulsion was found to be stable for more than 45 days. These results indicate that the optimized microemulsions need not to be refrigerated for enhancing its shelf-life and can be stored at room temperature.

\section{Conclusions}

In the present study, it may be stated the nanocarrierlike microemulsion-based hydrogel has immense potential to combat the problem related to the drug. In this study, this nanocarrier has appeared as one of the best biocompatible topical carrier, with noticeable threefold higher percutaneous permeation of benzyl benzoate through the stratum corneum and enhanced passive skin-targeting characteristics with respect to the conventional formulation. Furthermore, the microemulsion-based hydrogel presented the excellent ability of slow release and no irritation, which provides a probability for clinical application. Dermatokinetic modeling revealed the presence of sufficient concentration of drugs in the dermis layer of the skin. In a nutshell, the present studies corroborated that the developed nano-sized microemulsion-based hydrogel system can serve as efficient promoter of benzyl benzoate by increasing its availability at the site of action

Table VII. Physical Attributes of the Optimized Formulation

\begin{tabular}{lllll}
\hline S. Number & Days & \multicolumn{3}{c}{ Physical stability } \\
\cline { 3 - 5 } & & $4 \pm 2^{\circ} \mathrm{C}$ & $30 \pm 2^{\circ} \mathrm{C}$ & $45^{\circ} \mathrm{C} \pm 2^{\circ} \mathrm{C}$ \\
\hline 1 & 1 & $\sqrt{ }$ & $\sqrt{ }$ & $\sqrt{ }$ \\
2 & 7 & $\sqrt{ }$ & $\sqrt{ }$ & $\sqrt{ }$ \\
3 & 14 & $\sqrt{ }$ & $\sqrt{ }$ & $\sqrt{ }$ \\
4 & 28 & $\sqrt{ }$ & $\sqrt{ }$ & $\sqrt{ }$ \\
5 & 35 & $\sqrt{ }$ & $\sqrt{ }$ & $\sqrt{ }$ \\
6 & 45 & $\sqrt{ }$ & $>45$ days \\
Net result & $>45$ days & $>45$ days & & \\
\hline
\end{tabular}

\section{ACKNOWLEDGEMENTS}

Authors are thankful to M/s S.D. Fine Chemicals Ltd, Mumbai, India, for generously providing the gift samples of benzyl benzoate where as to $\mathrm{M} / \mathrm{s}$ Phospholipid $\mathrm{GmbH}$, Nattermannallee, Germany, for the ex gratia supply of Phospholipon S100. Financial grants obtained from the Department of Science and Technology (DST-INSPIRE), New Delhi, India, are duly acknowledged.

\section{COMPLIANCE WITH ETHICAL STANDARDS}

Conflict of Interest The authors confirm that this article's content has no conflicts of interest.

\section{REFERENCES}

1. Chosidow O. Scabies and pediculosis. Lancet. 2000;355:819-26.

2. Hengge UR, Currie BJ, Jäger G, Lupi O, Schwartz RA. Scabies: a ubiquitous neglected skin disease. Lancet Infect Dis. 2006;6(12):769-79.

3. Taplin D, Meinking TL, Chen JA, Sanchez R. Comparison of crotamiton $10 \%$ cream (Eurax) and permethrin $5 \%$ cream (Elimite) for the treatment of scabies in children. Pediatr Dermatol. 1990;7:67-73.

4. Guggisberg D, de Viragh PA, Constantin C, Panizzon RG. Norwegian scabies in a patient with acquired immunodeficiency syndrome. Dermatology. 1998;197:306-8.

5. Roberts LJ, Huffam SE, Walton SF, Currie BJ. Crusted scabies: clinical and immunological findings in seventy-eight patients and a review of the literature. J Infect. 2005;50:375-81.

6. Walton SF, Currie BJ. Problems in diagnosing scabies, a global disease in human and animal populations. Clin Microbiol Rev. 2007;20(2):268-79.

7. McCarthy JS, Kemp DJ, Walton SF, Currie BJ. Scabies: more than just an irritation. Postgrad Med J. 2004;80:382-7.

8. Tomalik-Scharte D, Lazar A, Meins J, Bastian B, Ihrig M, Wachall B, et al. Dermal absorption of permethrin following topical administration. Eur J Clin Pharmacol. 2005;61:399-404.

9. Bachewar NP, Thawani VR, Mali SN, Gharpure KJ, Shinghade VP, Dakhale GN. Comparison of safety, efficacy, and cost effectiveness of benzyl benzoate, permethrin, and ivermectin in patients of scabies. Indian J Pharmacol. 2009;41(1):9-14.

10. Alberici E, Pagani L, Ratti G, Viale P. Ivermectin alone or in combination with benzyl benzoate in the treatment of human immunodeficiency virus-associated scabies. Br J Dermatol. 2000;142:969-72.

11. Karthikeyan K. Treatment of scabies: newer perspectives. Postgrad Med J. 2005;81:7-10. 
12. Glaziou P, Cartel JL, Alzieu P, Briot C, Moulia-Pelat JP, Martin PM. Comparison of ivermectin and benzyl benzoate for treatment of scabies. Trop Med Parasitol. 1993;44:331-2.

13. Currie BJ, Harumal P, McKinnon M, Walton SF. First documentation of in-vivo and in-vitro ivermectin resistance in Sarcoptes scabiei. Clin Infect Dis. 2004;39:8-12.

14. Walton SF, Myerscough MR, Currie BJ. Studies in-vitro on the relative efficacy of current acaricides for Sarcoptes scabiei varhominis. Trans R Soc Trop Med Hyg. 2000;94:92-6.

15. Yewale C, Baradia D, Vhora I, Misra A. Proteins: emerging carrier for delivery of cancer therapeutics. Expert Opin Drug Deliv. 2013;10:1429-48.

16. Katare OP, Raza R, Singh B, Dogra S. Novel drug delivery systems in topical treatment of psoriasis: rigors and vigors. Indian J Dermatol Venereol. 2010;76:612-21.

17. Raza K, Negi P, Takyar S, Shukla A, Amarji B, Katare OP. Novel dithranol phospholipid microemulsion for topical application:development, characterization and percutaneous absorption studies. J Microencapsul. 2011;28(3):190-9.

18. Kreilgaard M. Influence of microemulsions on cutaneous drug delivery. Adv Drug Deliv Rev. 2002;254:77-98.

19. Baboota S, Al-Azaki A, Kohli K, Ali J, Dixit N, Shakeel F. Development and evaluation of a microemulsion formulation for transdermal delivery of terbinafine. J Pharm Sci Technol. 2007;61:276-85.

20. Chen H, Mou D, Du D, Chang X, Zhu D, Liu J, et al. Hydrogel thickened microemulsion for topical administration of drug molecule at an extremely low concentration. Int J Pharm. 2007;341:78-84.

21. Lawrence MJ, Rees GD. Microemulsion-based media as novel drug delivery systems. Adv Drug Deliv Rev. 2000;45:89-121.

22. Kamal MA, Iimura N, Nabekura T, Kitagawa S. Enhanced skin permeation of diclofenac by ion-pair formation and further enhancement by microemulsion. Chem Pharm Bull. 2007;55:368-71.

23. Peltola S, Saarinen-Savolainen P, Kiesvaara J, Suhonen TM, Urtti A. Microemulsions for topical delivery of estradiol. Int J Pharm. 2003;254:99-107.

24. DiBiase M, Rhodes C. Formulation and evaluation of epidermal growth factor in Pluronic-127 gel. Drug Dev Ind Pharm. 1996;22(8):823-31.

25. Yeon S, Chul J, Moo Y. Poly(ethylene oxide)-poly(ethylene oxide $) / \mathrm{ply}(\in-$ caprolactone) (PCL) amphiphilic block copolymeric nanospheres: Thermo-responsive drug release behaviours. J Control Rel. 2000;65:345-58.

26. Miyazaki S, Tobiyama T, Takada M, Attwood D. Percutaneous absorption of indomethacin from Pluronic F-127 gels in rats. J Pharm Pharmacol. 1995;47:455-7.

27. Escobar-Chávez JJ, López-Cervantes M, Naïk A, Kalia YN, Quintanar-Guerrero D, Ganem-Quintanar D. Applications of thermoreversible Pluronic F-127 gels in Pharmaceutical Formulations. J Pharm Pharm Sci. 2006;9(3):339-58.

28. Kawakami K, Yoshikawa T, Moroto EK, Takahashi K, Nishihara Y, Masuda K. Microemulsion formulation for enhanced absorption of poorly soluble drugs I. Prescription design. J Control Release. 2002;81:65-74.

29. Tansel C, Nursin G. Microemulsions. J Fac Pharm Ank. 1997;26(2):95-108.

30. Agarwal R, Katare OP, Vyas SP. Preparation and in-vitro evaluation of liposomal/niosomal delivery systems for antipsoriatic drug dithranol. Int J Pharm. 2001;228(1-2):4352.

31. Raza K, Singh B, Lohan S, Sharma G, Negi P, Yachha Y, et al. Nano-lipoidal carriers of tretinoin with enhanced percutaneous absorption, photostability, biocompatibility and anti-psoriatic activity. Int J Pharm. 2013;456:65-72.

32. Singh B, Mehta G, Kumar R, Bhatia A, Ahuja N, Katare OP Design, development and optimization of nimuslide-loaded liposomal systems for topical applications. Curr Drug Deliv. 2005;2:143-53.

33. Al Abood RM, Talegaonkar S, Tariq M, Ahmad MJ. Microemulsion as a tool for the transdermal delivery of ondansetron for the treatment of chemotherapy induced nausea and vomiting. Colloids Surf B: Biointerfaces. 2013;101:143-51.

34. Guth K, Schäfer-Korting M, Fabian E, Landsiedel R, van Ravenzwaay B. Suitability of skin integrity tests for dermal absorption studies in vitro. Toxicol In Vitro. 2015;29(1):11323.

35. Negi P, Singh B, Sharma G, Beg S, Raza K, Katare OP. Phopholipid microemulsion-based hydrogel for enhanced topical delivery of lidocaine and prilocaine: QbD-based development and evaluation. Drug Deliv. 2014;3:1-17.

36. Kogan A, Garti N. Microemulsions as transdermal drug delivery vehicles. Adv Colloid Interface Sci. 2006;123-126:36985.

37. Trotta M, Cavalli R, Uzagio E, Gasco MR. Phase behaviour of microemulsion systems containing lecithin and lysolecithin as surfactants. Int J Pharm. 1996;143:67-73.

38. Raza K, Singh B, Singla S, Wadhwa S, Garg B, Chhibber S, et al. Nanocolloidal carriers of isotretinoin: antimicrobial activity against Propionibacterium acnes and dermatokinetic modeling. Mol Pharm. 2013;10:1958-63.

39. Guterres SS, Weiss V, de Lucca FL, Pohlmann AR. Influence of benzyl benzoate as oil core on the physicochemical properties of spray-dried powders from polymeric nanocapsules containing indomethacin. Drug Deliv. 2000;7(4):195-9.

40. Zarur AJ, Ying JY. Reverse microemulsion synthesis of nanostructured complex oxides for catalytic combustion. Nature. 2000;403:65-7.

41. Gao ZG, Choi HG, Shin HJ. Physicochemical characterization and evaluation of a microemulsion system for oral delievery of cyclosporin A. Int J Pharm. 1998;161:75-86.

42. Kim CK, Ryuu SA, Park KM, Lim SJ. Preparation and physiochemical characterization of phase inverted water: oil microemulsion containing cyclosporine A. Int J Pharm. 1997;147:131-4.

43. Philip AK, Pathak K. Wet process-induced phase-transited drug delivery system: a means for achieving osmotic, controlled, and level A IVIVC for poorly water-soluble drug. Drug Dev Ind Pharm. 2008;34:735-43.

44. Cilek A, Celebi N, Tirnaksiz F. Lecithin-based microemulsion of a peptide for oral administration: preparation, characterization, and physical stability of the formulation. Drug Deliv. 2006;13:1924.

45. Rigg PC, Barry BW. Shed snake skin and hairless mouse skin as model membranes for human skin during permeation studies. J Invest Dermatol. 1990;94:235-40.

46. Hathout RM, Mansour S, Mortada ND, Geneidi AS, Guy RH. Uptake of microemulsion components into the stratum corneum and their molecular effects on skin barrier function. Mol Pharm. 2010;7:1266-73.

47. Moghadam SH, Saliaj E, Wettig SD, Dong C, Ivanova MV, Huzil $\mathrm{JT}$, et al. Effect of chemical permeation enhancers on stratum corneum barrier lipid organizational structure and interferon alpha permeability. Mol Pharm. 2013;10(6):2248-60.

48. Uchino T, Lefeber F, Gooris G, Bouwstra J. Characterization and skin permeation of ketoprofen-loaded vesicular systems. Eur J Pharm Biopharm. 2014;86(2):156-66. 